\title{
Non-dipping phenomenon in patients with essential hypertension with renal cysts: Dr. B. Afsar responds
}

\author{
Baris Afsar
}

Received: 29 April 2010/Accepted: 6 May 2010/Published online: 20 May 2010

(C) Springer Science+Business Media, B.V. 2010

Thanks to the important concerns raised by Anusionwu et al. about our recently published paper. We found that simple renal cysts were independently associated with nocturnal non-dipping in essential hypertensive patients [1]. Anusionwu et al. suggested that the actual and independent association of simple renal cysts and non-dipping phenomenon in essential hypertension is still unclear from our study and several other factors such as salt-sensitivity, renal function impairment and mineralocorticoid excess may play an important role for the development of non-dipping blood pressure.

First of all since our study was cross-sectional, we agree that cause and effect relationship cannot be drawn from this study. This was already mentioned as a limitation in our paper.

Second, not only aforementioned factors may be related with non-dipping but also many other factors and disease states can be related with non-dipping pattern [2]. For example, patients may have other causes of hypertension such as renovascular hypertension and we did not perform renal Doppler studies or renal vein sampling. We think that it is almost impossible to control and include all of these factors while conducting our study. However, we have no patients with secondary hypertension (based on patient's history) and we exclude one patient with adrenal mass in our study.

We consider our study as preliminary; only welldesigned prospective studies can demonstrate the cause and relationship between simple renal cysts and circadian blood pressure.

\section{References}

1. Afsar B, Afsar RE, Sen ST et al. (2010) Simple renal cysts and circadian blood pressure: are they related to each other in patients with hypertension? Int Urol Nephrol. doi: 10.1007/s11255-010-9734-7

2. Kanbay M, Turgut F, Uyar ME, Akcay A, Covic A (2008) Causes and mechanisms of nondipping hypertension. Clin Exp Hypertens 30(7):585-597
B. Afsar $(\bowtie)$

Department of Nephrology, Zonguldak Ataturk State

Hospital, Zonguldak, Turkey

e-mail: afsarbrs@yahoo.com 